\title{
Research on the Development of School Sports with Physical Health as a Starting Point
}

\author{
Peng Limin \\ Yunnan University of Traditional Chinese Medicine \\ Kunming,Yunnan, 650500 China
}

\begin{abstract}
Student Physical Health promotion is to improve our students' physical health of important initiatives. Article based on the "health promotion" theory puts forward new ideas to promote students' physical health. An important way to study is based on the school sports that is as a student of this fundamental physical health promotion, school sports is to promote students' physical health, students want to promote school sports. First, school sports should establish a life education, strengthen the concept of student life education; secondly, school physical education should become the main way to carry physical health; again, it should advocate students to do physical exercise as a way of life.
\end{abstract}

Keywords- Physical Fitness of Students; Health Promotion; School Sports; Responses

\section{INTRODUCTION}

School of Physical and Health Education is a mutually reinforcing relationship, their common goal is to have a purpose, and meaningful educational process of each student's health is conducted. Meanwhile, the school physical education for students in health education provides the main route, and school health education is to provide a broad space for development of school education. But some scholars currently are not on the "Student Physical Health Promotion" that gives a specific definition, but there is no analysis of relevant research reports from the Student Physical Health Promotion school sports angle. This article is based on health promotion and physical fitness of students this fundamental issue, school sports content is the core of Students' Health Promoting Schools how sport should be constructed.

On September 18, 2006, the State Sports General Administration and the Ministry of Education jointly announced the "Second National Physique Monitoring Report". The monitoring results show: Students' endurance, speed, power, strength quality declined, super obese students in the proportion rapidly increase in overweight and obesity in the city is close to a quarter of the boys, middle school vision defect rate has more than two-thirds of college students vision defect rate as high as $83 \%$. Since 1985, our students' physical health status was sustained downward trend, "hardware", namely the level of physical fitness of young students' physical quality, heart and lung function decline, high myopia, have a substantial increase in obese children. Along with these "hardware", it came the recession in geriatric younger age and young students "software" problem after another, afraid of hardships Figure cozy,
Willpower is weak in the anti-frustration ability. According to China's Compulsory Education Law, every school-age children and adolescents have nine years of compulsory education, schools should offer specialized sports programs for all students, educate and guide students to a planned exercise, enhance students' health, enhance physical fitness of students.

\section{RELATIONSHIP BETWEEN A STUDENT PHYSICAL HEALTH PROMOTION AND SCHOOL SPORTS}

Student Physical Health promotion is not in schooloriented sports that have become a river without water, without the present of this. Through schools, it enables students to develop lifelong sports habits, and actively to improve poor student lifestyle to minimize all kinds of health hazards, to help students through their own actions and efforts to achieve physical health. It is the only way to better the quality of education so that students become a lifelong healthy person. School sport is not only an important part of students 'physical health promotion, but also an important means of implementing, it is indispensable to promote students' physical health and vital support, in the sense that other disciplines cannot be replaced. Especially for students in the growth stage of speaking, school sports and physical fitness of the student body shape changes and even has a great impact on his life.

\section{StUdent PHYSICAL HEALTH AND PHYSICAL EDUCATION IN THE VIEW OF RESPONSE MEASURES}

\section{A. School Sports Establish a "Life Education" Concept}

School sports and life education are coupled. Life Education is education that focuses on human life; it is a teaching philosophy, but also a valuable pursuit. The purpose of education is to improve the quality of life of life. School sports should learn basic sports skills, promote student physical health, and improve quality of life. Both the common goal is to improve the quality of life. Learning life education is based on full understanding of human psychology, physiology, etc. on the basis of knowledge, which is what the school sports can be reflected. Natural life education, spiritual life education, values education and wisdom of life in the life education are life sports content of education school. 


\section{B. Change the Traditional Ideas; Establish a Comprehensive Development of Quality Education Thought}

Educational Thought and intellectual thought shift focus to establish the concept of great importance to the health of students' education. Intellectual's role is very large, especially in the knowledge-based economy, but blindly emphasis on intellectual, physical and mental health neglect, and then this kind of education is a failure of education. Currently, the voice of China's educational reform is wave after wave. Exam-oriented education is for quality education to achieve a thorough transformation, changing concepts of education and improving the quality of education is imminent, Chinese education has come to the old educational system, a complete break with the old concept of education time. Only on the basis of innate qualities, can it be acquired through education and training, in order to develop and improve the basic quality of people. And healthy physique and good mental quality are important parts of people's overall quality that is an important part of the 21st century talent quality. Healthy body and mind is the carrier of knowledge and ability to promote the comprehensive development of sports that have an essential role. Without a good level of fitness and health, it is difficult to adapt to modern society intense social competition. This requires government departments attach importance to intellectual, we cannot ignore the sport, we should pay attention to sports in terms of ideology, give institutional safeguards to ensure on school sports, extracurricular physical exercise various systems have been implemented.

Values above each sport have their own set of curriculum development understanding and views, and on the development of school physical education curriculum objectives, content, implementation and evaluation of curriculum elements vary. In fact, there are not enough of these types of value orientation. And there is certain onesidedness. Comprehensive development of quality education requires curriculum development in school sports of value orientation to be diverse. And it must be fused advantage of a variety of value orientation, which not only pays attention to the needs of society, but also should be concerned about the development of students. Especially in today's Student Physical Health under the reduction in the level of the situation, and it should raise the level of physical health that is more important and the development of students in the first row.

\section{HEALTH PROMOTION STANDARDS: FocUs INDEX VALUE}

Youth Physical Health Standard is to quantify the means to measure the physical health conditions, rational or not bound to its target to guide the relationship between school physical education, but it also will affect the physical condition of students. Students are from China's current physical health standards, there are some problems. Mainly as follows: 1) lack of operability. Step test is the index system testing, which had greater difficulty of the operation, the standard is difficult to control, and long duration, which leads to reduce effectiveness. Meanwhile, the maximum correlation step experiments with oxygen uptake capacity is not high, nor aerobic endurance training for students to play better role in promoting, which easily leads to a formal test, but it did not play a substantive process of exercise guiding role; 2) index structure is irrational. It is said that, we find that students are from the current standard of physical health, the evaluation index mainly reflects the student's speed and power capabilities, such as $50 \mathrm{~m}$ run and standing long jump. And they lack of coordination and sensitive indicators of physical ability, for adolescents, sensitive qualities in rapid development of coordination "sensitive period", if the time does not pay attention to these qualities exercises, they will affect future athletic ability. Therefore, we should further strengthen the construction of rationality of index system and it becomes necessary.

Holistic principle thinks that any one is organic whole system in the world, not only internally between the various components that are interrelated elements, but also the organic connection between the system and the external environment. When we deal with the problem, it should be a holistic approach, starting from the analysis of the relationship between the various components of the overall relationship between the internal and the external environment. We should reveal and grasp its overall properties. Herein school physical education curriculum as a whole refers to physical education, including extracurricular sports activities such as morning exercises, large recess sports, extracurricular physical exercise and sports, various sports clubs, interest groups and members activities and other aspects of activities. School sports curriculum development of this paper is on the overall development of curricular sports and extracurricular sports, holistic aims are to enhance students' physical fitness. Therefore, in the school sports curriculum development process, we must adhere to the principle of integrity.

\section{Challenges AND Thinking that SchoOl OF PHYSICAL EDUCATION REFORM FACES}

In the new century, as school sports major educational projects, new sports and health curriculum standards and textbooks have been positive after the pilot entered the implementation phase. New sports courses and materials reflects the thinking of the overall school curriculum reform education to improve students' overall physical and mental health as the core. School of Physical Education and its fundamental responsibilities are to improve worker's physical and mental health of all students, school PE is not only to teach sports knowledge, technical skills, to improve their physical fitness, but also to improve students good psychological quality, good mood emotions, as well as a strong will and a spirit of cooperation and human coexistence. Therefore, as a sports teacher in the new period, they must have a comprehensive and basic understanding of the concepts of education, professional knowledge and ability that the PE and health curriculum building should have. We need to improve the quality of physical education teachers. Improving PE Teachers factors includes changing concepts of education, updates knowledge and improves 
skills and professional ethics. Because the main problem is to be solved effectively in good physical health of students currently, the key to the successful implementation of the implementation of the new "Sports and Health" course is the PE teachers.

\section{A. Student Awareness of Physical Exercise is Not Strong}

First, you can be sure that students' sense of physical exercise has generally higher identity, but the students understanding of sports only stay on the surface, interested in sports cannot be converted. Secondly, some students in physical education are afraid of hardships, the choice of sports tend to choose the interior sport with sweat less, the lack of certain physical training, or some students because of their own reasons, do not like participate in sports, and thus reach a good training effect, let alone enhance physical fitness. Finally, students' extracurricular physical exercise is not enough. Current students in extracurricular exercise mainly rely on conscious behavior of individual students and organized student sports government should provide more support. The government attaches great importance to students' physical health. Every five years the National Student Physical Health research and physical health for students the continuous decline in the status quo that issued a series of policy documents. If government is to not only grasp the direction and macro-control, while at the micro level the implementation of the unity of the files and instructions to provide more material for our school sports and spiritual support, it is undoubtedly to our school sports plug in the wings.

\section{B. Schools Should Strengthen the Emphasis on Physical Education}

To reinforce the importance of school physical education, we should ensure the health of students in the first place. The primary task of the school is to strengthen the construction of sports equipment for students to provide basic protection of physical exercise. Secondly, measures are to improve physical education teachers and students, enthusiasm for sports, the sport is a realization of student health; student training is the means of lifelong sports consciousness, rather than as a physical education furnishings and artifacts. For present physical health, many experts called the sports scores included in the college entrance examination score, which should be encouraged by all sports people, when physical education can be proud, it should truly recover their value. However, this does not mean that our burden light. On the contrary, schools and teachers should think carefully about the next development of school sports. If you cannot change the status quo essentially from the teaching process from the concept that if $\mathrm{PE}$ remains at the level of the entrance examination, which is tantamount to more than just a standard test, the next PE still cares, so we are looking forward PE that is still not, but only piecemeal, temporary cure. Therefore, we should start from the fundamental purpose of starting school sports, to clarify the value of school sports, so everyone heartfelt loves sports.

People-oriented curriculum enhances students' physical health Sport that aims to enhance physical fitness, enhance physical fitness that is a fundamental physical education. Whether it is "physical theory" or "skill" theory, the starting point is to enhance students 'physical fitness, to increase students' health. We enhance physical fitness through multiple means; our goal is to promote health, to improve physical health.

The status quo of physical education curriculum reform should be in accordance to the physical health status of the students, and the school should be in accordance to the school itself. The actual situation of teachers should further reform of teaching content, means, methods, and establish student needs. Student love universal, suitable sports for human shape, sports teaching contents and methods of physiological, metabolic and psychological characteristics. It is student-centered, so that the overall development of "Health First" and the students really get implemented, so that school sport really shine its vitality. So, we should give students choice, the teacher should have a targeted physical exercise, "Happy Sport" does not mean do not exercise load. No matter what form of sport, as long as the students like, we can enhance physical fitness, we are worth learning and learning. In addition to set up a special theory courses, we need targeted guidance on exercise methods, so that students learn scientific methods in order to benefit from lifelong fitness.

\section{CONCLUSIONS}

Development of Chinese School Physical Education cannot be avoided and it will focus on the following issues: in the coming decades, will school physical education become mainstream education? Will government policy continue to emphasize health and fitness? What does Future Chinese school physical education look like? To answer these questions it accurately is difficult. First, the promotion of health and fitness will continue to be the core task of Chinese school physical education, school physical fitness test results will be the evaluation of schoolwork and education authorities work an important indicator. Second, network, video games, cell phones and other modern technology will have an impact on school physical education; what physical education teachers as well as administrative officials must consider is how to use these technologies to prevent children becoming obese patients, while improving physical education teaching quality. Third, the school physical education work closely correlated with national child policy toward strict one-child policy that will limit any possible cause bodily injury or dangerous student sport into the school PE class. Fourth, the deterioration of the air quality will have an impact on school physical education, outdoor sports activities have to consider the impact of air quality on students' health. Fifth, the support of the Chinese government, health-oriented national policies, public health awareness increases, increasing the country's economic strength, physical health are to promote the implementation of the project that will change the current unsatisfactory in many places, we should create Chinese Physical Education Health good environmental development. 


\section{Reference}

[1] Chen Suqin. Construction urban community public space [J] Sichuan Institute of Technology (Social Sciences), 2009, 05: 43-47.

[2] Yu Jian. On the health of urban public space design [J] art education research, 2013,12: 40-42.

[3] Fang Xin. Urban public space design activity and human behavior [J] Chongqing Jianzhu University, 2004, 02: 5-8.
[4] Li Yali. On the public space design millet Ale Chinese elements in expression [J] Packaging Engineering, 2012, 02: 136-138.

[5] Wu Xuejin. Urban communities livable public space research [D]. Central China Normal University, 2010. 